\begin{tabular}{|c|c|c|c|c|c|}
\hline & \multicolumn{5}{|c|}{$\%$ Correct answers } \\
\hline & $\begin{array}{l}\text { Community } \\
\mathrm{N}=813\end{array}$ & $\begin{array}{l}\text { Hospital } \\
n=532\end{array}$ & $\begin{array}{l}\text { Respiratory } \\
\text { interest } \\
n=976\end{array}$ & $\begin{array}{l}\text { Attended LRT Event } \\
n=168\end{array}$ & Overall \\
\hline Generic Salbutamol MDI & 51.0 & 50.9 & 49.0 & 58.9 & 51.1 \\
\hline Ventolin Evohaler & 36.5 & $18.6^{*}$ & 29.9 & 33.5 & 29.2 \\
\hline Symbicort 200 turbohaler & 50.2 & 45.7 & 50.4 & $66.5^{\#}$ & 47.7 \\
\hline Seretide 250 evohaler & 36.9 & 36.5 & 38.6 & $58.2^{\#}$ & 36.0 \\
\hline Seretide 500 accuhaler & 50.6 & 50.4 & $53.1^{+}$ & $62.7^{\#}$ & 49.8 \\
\hline Fostair $100 \mathrm{MDI}$ & 52.4 & $43.6^{*}$ & $51.9^{+}$ & 50.6 & 48.7 \\
\hline Spiriva Handihaler & 49.9 & 49.4 & $52.6^{+}$ & 55.7 & 49.3 \\
\hline
\end{tabular}

could add a sense of value and improve responsible prescribing, including renewed focus on stepping down patients on high potency treatments when they are stable or have experienced no benefit, and always using a spacer with an MDI. Knowledge of which inhalers provide best value is also important for prescribers when choosing between evidenced based alternatives.

\section{P244 ASSESSING TRAINING VALUE AND EDUCATIONAL SUPERVISION IN SPR POSTS}

doi:10.1136/thoraxjnl-2012-202678.305

'D Menzies, ${ }^{2} \mathrm{NA}$ McAndrew, ${ }^{3} \mathrm{H}$ Fowles, ${ }^{3} \mathrm{R}$ Robinson, ${ }^{4} \mathrm{P}$ Flood-Page. ${ }^{1} \mathrm{Glan}$ Clwyd Hospital, Rhyl, Wales; ${ }^{2}$ Wrexham Maelor Hospital, Wrexham, Wales; ${ }^{3}$ Wales Respiratory Medicine SpR Training Scheme, Wales; ${ }^{4}$ Royal Gwent Hospital, Newport, Wales

Both the ongoing evaluation of training and the possible reduction in $\mathrm{SpR}$ training numbers makes it imperative to identify which SpR training posts offer the best educational value. Consultants may overestimate or overstate the training opportunities at their hospital. The JRCPTB "Post Assessment" form is rather non-specific and poorly used. The Respiratory STC in our region undertook to obtain feedback from respiratory SpR's about the diversity and quality of training and educational supervision. A questionnaire was e-mailed to all SpR's asking about training opportunities in clinical areas defined by the respiratory curriculum and the JRCPTB Respiratory PYA form; asking about exposure to a given service or specialty rather than just its presence in the hospital (e.g. domiciliary NIV, sleep medicine, thoracoscopy), and the quality of training in that area, (score 1-5, poor - excellent), and how they rated their educational supervision overall. Responses were to include posts previously and currently worked. Trainees sent 40 evaluations on the 14 training hospital in our region, (range 1-6 per hospital). A composite score for training opportunities was derived (maximum possible score for specialty and service areas 71). Scores for individual hospitals ranged from 17.3-43.6 (median 32) and the score for supervision at those sites ranged from 3.3-5 (median 4.3). Hospital identifiable results were tabulated and circulated firstly to trainers and later to trainees. Free text comments were handled more confidentially. Despite some reservations, (e.g. the perspective held by a junior SpR in completing the survey and a possible bias away from broad based DGH training), the STC regarded this as a useful exercise and the questionnaire will be modified by iteration and trainees will complete one after each post. Consultants will be asked to complete the same questionnaire for cross reference. Anecdotally, some units have already begun addressing some issue raised, perhaps in response to a need to "compete". These results may motivate hospitals to improve their training of SpR's as well as informing decisions on which posts should be retained and which should not.

\section{P245 STANDARDISATION OF BRONCHOSCOPY TRAINING ACROSS YORKSHIRE AND HUMBER DEANERY}

doi:10.1136/thoraxjnl-2012-202678.306

'F Chowdhury, ${ }^{2} \mathrm{~A}$ Gondker, 'N Acharya, 'R Naseer, 'I Hill, ${ }^{3} \mathrm{~J}$ Hogg, ${ }^{2} \mathrm{~J}$ Kastelik, 'S Renshaw, 'S Bianchi. 'Sheffield Teaching Hospitals, Sheffield, England, United Kingdom; 'Hull Royal Infirmary, Hull, England, United Kingdom; ' $P$ Pinderfields Hospital, Wakefield, England, United Kingdom

Background Reduced exposure to bronchoscopyis a key issue for respiratory trainees with effect on their confidence in undertaking the procedure and thus patient safety. Studies have shown that simulation improves confidence in bronchoscopy skills but do not explore the most optimal teaching methods.

Aim To assess two different methods of delivering bronchoscopy simulation training

Methods Two half day simulation bronchoscopy courses were designed independently within the Yorkshire and Humber Deanery. Course 1 concentrated on providing a knowledge based training consisting of a didactic lecture followed by equal time spent on a Symbionixsimulator and on the BTS e-learning hub website. Course 2 provided pre-course material in the form of BTS guidelines and bronchoscopy procedure pocketbook. The course focused on handson simulation training using a bronchoscopy manikin and the Symbionix simulator. All candidates completed pre and post course Likert scale questionnaires in six areas relating to participant knowledge and confidence in using a bronchoscope.

Results Overall 30 trainees; 15 in each course were evaluated. Candidates had performed between 0 to $>300$ previous bronchoscopies and were from across the SpR years. Both courses delivered significant improvement in confidence scores in all of the six areas assessed. The greatest improvement was found in confidence levels in technical ability (see table 1). Course 1 candidates showed a greater confidence improvement in factual skills (such as knowledge of contra-indications of the procedure and anatomy). Course $2 \mathrm{dem}-$ onstrated that $93 \%$ of candidates agreed that the simulator helped to improve technical ability in contrast to $100 \%$ with manikin exposure. $100 \%$ of candidates found the pocketbook was a useful adjuvant to the course with $93 \%$ agreeing that they would find this useful to complement their training.

Conclusions A combined and standardised bronchoscopy simulation course incorporating lectures and pre-course materials but focusing on hands on experience on both a manikin and a simulator is therefore considered to provide greatest educational benefit. This course is now active in Yorkshire and the Humber and is to be mandated for all new trainees to the programme. Each SpR will also be re-assessed after a 3-month period incorporating a competencybased assessment approach. 
Abstract P245 Table 1

\begin{tabular}{|c|c|c|c|c|c|c|}
\hline & \multicolumn{3}{|c|}{ East and West Yorkshire } & \multicolumn{3}{|c|}{ South Yorkshire } \\
\hline & $\begin{array}{l}\text { Mean Improvement } \\
\text { score (SD) }\end{array}$ & $\%$ Improvement & p value & $\begin{array}{l}\text { Mean Improvement } \\
\text { score (SD) }\end{array}$ & $\%$ improvement & p value \\
\hline Confidence in knowing the indications for bronchoscopy & $0.6(0.63)$ & 12.0 & 0.007 & $0.7(0.72)$ & 13.4 & 0.008 \\
\hline Confidence in knowing the contra-indications for bronchoscopy & $1.0(1.06)$ & 20.0 & 0.007 & $0.6(0.74)$ & 12.0 & 0.013 \\
\hline Confidence in accurately identifying all normal anatomy & $1.1(0.52)$ & 22.6 & $<0.001$ & $0.8(0.77)$ & 16.0 & 0.006 \\
\hline Confidence in knowing the complications for bronchoscopy & $0.7(0.72)$ & 13.4 & 0.008 & $0.5(0.64)$ & 9.4 & 0.020 \\
\hline Confidence in knowing the safe limits of conscious sedation & $1.2(1.08)$ & 24.0 & 0.003 & $0.9(1.03)$ & 18.6 & 0.008 \\
\hline Confidence in technical ability in handling the bronchoscope & $1.1(0.64)$ & 22.6 & 0.001 & $1.1(1.03)$ & 21.4 & 0.004 \\
\hline $\begin{array}{l}\text { Confidence in consenting the patient and quoting accurate } \\
\text { complication rates }\end{array}$ & - & - & - & $1.0(1.06)$ & 20.0 & 0.007 \\
\hline $\begin{array}{l}\text { Confidence with the correct dosage of lidocaine when anaesthetising } \\
\text { the airways }\end{array}$ & - & - & - & $1.3(1.23)$ & 26.6 & 0.003 \\
\hline $\begin{array}{l}\text { Confidence in using the appropriate sampling technique for each } \\
\text { suspected pathology }\end{array}$ & - & - & - & $1.5(0.99)$ & 29.4 & 0.002 \\
\hline
\end{tabular}

Authors 1 and 2 are first authors

\section{P246 RESPIRATORY PATIENT ACTIVITY, PHYSICAL EXERCISE IN NORMAL INDIVIDUALS, AND TELEHEALTH PREDICTION OF AIR POLLUTION}

doi:10.1136/thoraxjnl-2012-202678.307

M Morrison, KM Prentice, LJ Anderson, K Mcdowall, E Hopkins, L Macleod-Kennedy, JK Anderson, I Beverland, S Sneddon, K Anderson. Dept of Respiratory Medicine, University Hospital Cross house, Kilmarnock, Kilmarnock, Scotland

Background While air pollution is associated with morbidity and mortality in patients with respiratory and cardiac disease, there are also effects in normal individuals particularly if exercising on days when pollutants are high. The accepted advice on these days is to reduce exposure by restricting activity or remaining indoors. Consequently, in the European Union, high PM10 levels in 2005 caused $625 \mathrm{M}$ individual restricted activity days, encouraging national telehealth programmes, which incorporate this approach. Know and Respond, introduced in Scotland in February 2012, informs individuals by text, email, or landline message of the next day's air pollution prediction.

Study Five main focus groups were contacted-COPD patients registered with our LTOT service $(n=20$, age $55-73)$, in-patient respiratory patients ( $n=6$ COPD and $n=7$ asthmatics, age $24-75)$, regular recreational joggers from central Glasgow $(n=25$, age $24-30)$, competitive athletes ( $n=15$, age 21-26), and a group of occasional exercisers, who were predominately sedentary otherwise $(n=15$, age 25-30). Questions were asked about multimedia access, basic knowledge of air pollution and its' influence on daily activities.

Results Only 5 of the LTOT patients had internet access, and 7 had text receiving mobiles. All other subjects had internet access, and text phones. In the in-patient asthmatic group most were aware of the links between air pollution and health (6/7) and would change their exercise habits. In comparison only one COPD patient reported a link and consideration for air pollution when exercising. Some of the competitive athletes (13/15) and occasional exercisers (9/15) were aware of PM2.5 as a risk pollutant which might influence their choice of activity, but none of the joggers, who all ran regularly even during the high levels of air pollution in Glasgow during March 2012 when unseasonal weather patterns drew pollutant dusts from Europe across Scotland.

Conclusion We would reasonably contend that the aim of Know and Respond is justified given the known effects of air pollution however we acknowledge that awareness of the background relevance of air pollution is extremely variable. Know and Respond patient cards have been sent to general practise surgeries nationally to encourage patients to register with this free service.

\section{P247 IMPACT OF IMPLEMENTING COPD SELF MANAGEMENT PLANS \& RESCUE MEDICATIONS ACROSS 3 HOSPITALS}

doi:10.1136/thoraxjnl-2012-202678.308

${ }^{1} \mathrm{H}$ Khachi, ${ }^{2} \mathrm{M}$ Hodson, ${ }^{1} \mathrm{~V}$ Welsby, ${ }^{3} \mathrm{R}$ Hudson, ${ }^{4} \mathrm{CM}$ Roberts. ${ }^{1}$ Barts Health NHS Trust, London, UK; ${ }^{2}$ Homerton University Hospital NHS Foundation Trust, London, UK; ${ }^{3}$ UCL Partners, London, UK; ${ }^{4}$ BartsThe London School of Medicine and Dentistry, Queen Mary University of London, London, UK

Introduction COPD is the second leading cause of emergency admissions in the UK. National guidelines for managing COPD advise that patients at risk of having or those who have had an exacerbation of COPD should be given self-management advice that encourages them to respond promptly to their symptoms. As part of this, they should be given a course of oral antibiotics and corticosteroids to keep at

Abstract P247 Table 1

\begin{tabular}{lcccc}
\hline Hospital & \multicolumn{3}{c}{ COPD Readmission Rate \% } \\
\cline { 2 - 5 } & \multicolumn{2}{c}{$\begin{array}{l}\text { 30 day readmission for patients given and not given self } \\
\text { management plan \& rescue medication }\end{array}$} & $\begin{array}{l}\text { 90 day readmission for patients given and not given self } \\
\text { management plan \& rescue medication }\end{array}$ \\
\cline { 2 - 5 } & Not Given (\%) & Given Rescue Packs \& Plan (\%) & Not Given (\%) & Given Rescue Packs \& Plan (\%) \\
\hline $1(n=100)$ & 18.8 & 10.3 & 28.1 & 25.0 \\
$2(n=92)$ & 16.3 & 12.2 & 23.3 & 22.2 \\
$3(n=265)$ & 38.5 & 21.5 & 44.5 & 38.5 \\
Total & 29.7 & 17.2 & 36.6 & 32.3 \\
\hline
\end{tabular}

